\title{
Scottish general practitioners' willingness to take part in a post-retirement retention scheme: questionnaire survey
}

\author{
Margaret Chambers, Iain Colthart, Brian McKinstry
}

Concern is growing about a crisis in recruitment and retention in general practice in the United Kingdom. ${ }^{1}$ Although national statistics for Scotland show continued increases in the number of unrestricted general practitioner principals, the trend is slowing. More worryingly the numbers show a decrease in full time practitioners every year for the past 10 years. $^{2}$ Large increases in the numbers of female doctors, who are more likely to have reduced working commitments, add to the crisis at a time when the demand for general practitioners is rising.

There is evidence that general practitioners are retiring earlier, ${ }^{4}$ and we therefore undertook a survey of all unrestricted principals over the age of 55 practising in Scotland, to investigate their intentions for retirement and assess their interest in a retention scheme along the lines of the retainer scheme for general practitioners. ${ }^{5}$

\section{Method and results}

The 15 primary care NHS trusts in Scotland provided the means for contacting all general practitioner printo complete an anonymous questionnaire containing both open and closed questions, which was piloted on a group of general practitioners and showed good face validity. The questionnaire requested details of doctors' retirement plans, of reasons if retirement was planned before the age of 60 , and of any interest in a retention scheme. The type of scheme preferred by general practitioners was also explored.

We identified 487 practising general practitioner principals aged 55 and older and received replies from $348(72 \%)$. The returned questionnaires had a high rate of completion (95\% were satisfactorily completed). We found no difference in age and sex of the non-responders to that of the responders.

Of the 333 respondents to the question of age of intended retirement 20\% (68) planned to retire before $60,51 \%(170)$ at 60 , and $29 \%$ (95) planned to continue beyond 60 . Ninety four doctors who planned to retire before the age of 60 reported they had made additional financial provision. Eighty one per cent (55) of those intending to retire before 60 cited excessive workload as the reason.

Two hundred and forty three (70\%) doctors indicated an interest in a retention scheme. Around two thirds $(155,65 \%)$ indicated they would prefer to be retained by their current practice, and $141(58 \%)$ expected to continue working in the scheme for longer than two years.

The table shows how many sessions the respondents would ideally like to work and what activities they would like to undertake in a session. Teaching interested 90 (37\%) doctors, and of these 79 (88\%) would like to teach medical students, $56(62 \%)$ general practitioner registrars, and 10 (11\%) “others," which included nurses, staff, underperforming doctors, and hospital registrars. cipals over the age of 55 . The doctors were requested
Other activities indicated by 15 doctors included audit, out of hours work, minor surgery, practice visits, chronic disease management, mentoring, methadone supervision, information technology, hypnosis, and acupuncture.

\section{Comment}

This survey indicates that many experienced general practitioners on the point of retirement would be interested in a retention scheme along the lines of the existing retainer scheme. Even if only half of those who expressed an interest in such a scheme applied it would provide the equivalent of 40 full time posts in Scotland, which could partly offset the recruitment crisis. In addition these experienced general practitioners could provide a valuable education resource.

The survey also indicates that of those general practitioners in Scotland now aged 55 and above at least $71 \%$ plan to retire at or before the age of 60 , with excessive workload being cited as the main reason and other interests as the second reason. This concurs with other survey results. ${ }^{4}$ Several experienced general practitioners commented that, to provide an attractive worthwhile service, a retention scheme must be flexible and well remunerated.

We thank all the medical directors in the Scottish primary care trusts for supplying information; Stuart Macpherson, David Love, and Jim Alcock for their support; and Louise Crolla for administrative support.

Contributors: MC designed the study, helped analyse the results, and wrote the paper. IC entered the data, helped analyse the results, and helped write the paper. BMcK helped design the study, analysed the results, and helped write the paper. MC is guarantor.

Funding: NHS Education for Scotland and Lothian Primary Care Trust.

Competing interests: None declared.

1 Young R, Leese B. Recruitment and retention of general practitioners in the UK: what are the problems and solutions? Br J Gen Pract 1999;49: 829-33.

2 NHS Scotland Information and Statistics Division. Workforce statistics. Edinburgh: ISD, 2003. www.show.scot.nhs.uk/isd/NHSiS_resource/ Workforce/workforce_statistics.htm (accessed 23 Apr 2003).

3 Scottish General Practitioners Committee. The reality behind the rhetoric: a survey of the views of GPs in Scotland on morale, service provision and priorities for improving primary care. Edinburgh: BMA Scotland, 2001.

4 Luce A, Firth-Cozens J, van Zwanenburg T, Tinwell C. Predicting early retirement in general practice: relationship of retirement plans to job factors, stress and quality. Interim report. Newcastle upon Tyne: Centre for Clinical Psychology and Healthcare Research, Northumbria University, 2001.

5 NHS Education for Scotland. The GP retainer scheme in Scotland. Edinburgh: NES, 2001.

(Accepted 25 September 2003)

Number of sessions and type of activities that respondents in the questionnaire survey would like to undertake in retained posts

\begin{tabular}{lcccccc} 
& Total No of & \multicolumn{5}{c}{ Activities } \\
\cline { 3 - 7 } No of sessions & respondents & Surgeries & Visits & Admin & Teaching & Other \\
\hline 1 & 2 & 2 & 1 & 0 & 1 & 0 \\
\hline 2 & 77 & 76 & 23 & 10 & 29 & 5 \\
\hline 3 & 80 & 80 & 31 & 17 & 22 & 3 \\
\hline 4 & 84 & 81 & 43 & 15 & 38 & 7 \\
\hline Total & 243 & 239 & 98 & 42 & 90 & 15 \\
\hline
\end{tabular}

NHS Education for Scotland, Lister Postgraduate Institute, Edinburgh EH8 9DR

Margaret Chambers associate dean (flexible training) Iain Colthart researcher Brian McKinstry director of research Correspondence to: M Chambers margaret.chambers@ nes.scot.nhs.uk

BMJ 2004;328:329 